\title{
O SOCIODRAMA COMO METODOLOGIA DA PESQUISA
}

\author{
Neide Feijó ${ }^{1, *}$ (D), Lúcio Ferracini (1)
}

\begin{abstract}
RESUMO
Realizamos uma pesquisa-ação junto aos estudantes de um Curso de Psicodrama, com o objetivo de conhecer as características valorizadas para um pesquisador. Com relação ao Sociodrama como método, evidenciamos a facilidade de recolher, analisar e validar os dados com o próprio grupo, paralelamente a uma análise crítica das informações obtidas. Consideramos que essa metodologia facilitou a reflexão, a tomada de decisões e construção de estratégias de enfrentamento para as situações que os próprios estudantes vivenciavam enquanto pesquisadores.
\end{abstract}

PALAVRAS-CHAVE: Sociodrama; Pesquisa; Pesquisa qualitativa; Pesquisa-ação.

\section{SOCIODRAMA AS A RESEARCH METHODOLOGY}

\begin{abstract}
We conducted an action research with students of the Psychodrama Course, with the objective of identifying the characteristics valued by a researcher. With regard to Sociodrama as a method, we show especially the greater ease of collecting, analyzing and validating the data with the group itself, while also performing a critical analysis of the information obtained. Lastly, to acknowledge that this methodology allowed facilitated reflection, decision making and construction of coping strategies for the situations that the students themselves experienced as researchers.
\end{abstract}

KEYWORDS: Psychodrama; Research; Qualitative research; Action research.

\section{SOCIODRAMA COMO METODOLOGÍA DE INVESTIGACIÓN}

\section{RESUMEN}

Realizamos una investigación acción, con estudiantes del Curso de Psicodrama, con el objetivo de conocer las características valoradas por un investigador. Destacamos el Sociodrama como método, especialmente, la mayor facilidad para recolectar, analizar y validar los datos con el propio grupo, en paralelo a un análisis crítico de la información obtenida. Finalmente, considerar que esta metodología facilitó la reflexión, la toma de decisiones y la construcción de estrategias de resolución de las situaciones que vivieron los propios estudiantes como investigador.

PALABRAS CLAVE: Sociodrama; Investigación; Investigación cualitativa; Indagación activa.

1. Escola Superior de Saúde Jean Piaget - Vila Nova de Gaia, Portugal.

2. Centro Universitário das Faculdades Metropolitanas Unidas, Departamento Ciências da Saúde/Psicologia - São Paulo (SP), Brasil *Autora correspondente: neide.feijo@gaia.ipiaget.pt

Editor de seção: Fernando Costa Cordovio

Recebido: 02 Fev 2021 | Aceito: 07 Maio 2021 


\section{INTRODUÇÃO}

"O convite à pesquisa é, então, uma versão científica do convite ao encontro..."

(Brito, 2006, p. 31)

Ao realizarmos a presente pesquisa, direcionamos nosso interesse para o sociodrama como metodologia da pesquisa. Atualmente, a metodologia qualitativa é uma realidade praticada por pesquisadores reconhecidos no meio acadêmico. Moreno (2008) argumentava que a ontologia da ciência e os objetos de pesquisa não são os mesmos em todas as ciências e não são sempre meros objetos, em que se podem realizar generalizações. $\mathrm{O}$ autor já pretendia o reconhecimento dos seus trabalhos na categoria de pesquisa científica.

Não conseguiríamos explicitar melhor a importância do sociodrama como metodologia de pesquisa do que o faz o Brito (2006, p. 39):

Moreno nos legou uma metodologia que permite transitar entre os números, as palavras, os silêncios e os movimentos, sem ignorar as posições estáticas e as expressões gráficas. Podemos fazer pesquisa empregando todas as possiblidades de interação humana, inclusive as imaginárias.

Optamos por utilizar o termo "sociodrama" no contexto das metodologias de pesquisa, pois assim o encontramos em diversos trabalhos de sociopsicodramatistas. Podemos destacar a obra de Nery (2010) que traz dois capítulos muito esclarecedores a esse respeito: O sociodrama: um método de intervenção e de pesquisa social e Análise de sociodrama para produção de conhecimento cientifico.

Buscando na literatura sustentar nossas afirmações de que o sociodrama é uma importante estratégia de pesquisa, apresentamos as afirmações de Figusch (2010), para quem o sociodrama é uma ferramenta de pesquisa-ação, numa abordagem qualitativa da pesquisa. A ação dramática, inerente ao sociodrama, é o meio privilegiado de compreender o processo de desenvolvimento e transformação dos grupos.

A metodologia sociodramática possibilita a clarificação de situações de difícil enfrentamento; produz conhecimento sobre a realidade de um grupo ou comunidade e possibilita a coleta de dados, tal como percebidos pelas pessoas envolvidas.

As vantagens da utilização dessa metodologia são: a participação efetiva do sujeito; a busca da autonomia; a análise das próprias ações no fazer grupal; a conquista de papéis sociais; a evidência das potencialidades do ser humano; a manutenção da profundidade suficiente e necessária para os entendimentos desejados na pesquisa (Ramos, 2008); além da oferta de suporte e empoderamento diante das problemáticas atuais da sociedade (Iunes \& Conceição, 2017).

A metodologia sociodramática facilita o emergir das emoções, histórias de vida, percepções, dentre outros conhecimentos subjetivos do grupo, e nesse processo, paradoxalmente, a maior objetivação do fenômeno estudado pode ocorrer (Fleury \&Marra, 2010). As questões da subjetividade, objetivação e neutralidade do pesquisador são frequentemente preocupações de um processo de pesquisa, que a dinâmica do método sociodramático possibilitará evidenciar os conflitos e as estratégias de superação pelo grupo.

O sociodrama, ao trabalhar os conflitos interpessoais e grupais, busca dar voz aos atores sociais e tem como sujeito o grupo. Para seu desenvolvimento, o sociodramatista tem à sua disposição todo o legado da teoria moreniana (Nery, 2010).

Esse processo de transformação social, além de proporcionar a participação, também traz consigo o princípio do "aqui e agora" ou de momento, como enfatiza Rozados (2018).

Outro aspecto do sociodrama que favorece a pesquisa é o de permitir colher e avaliar os dados de forma contínua, integrada e em conjunto com os próprios atores sociais. Esse ponto é muito importante e valorizado pelos estudiosos em pesquisa qualitativa (Gomes, 2015).

A pesquisa que realizamos vai ao encontro dos pontos aqui destacados, ao propor como objetivo principal conhecer as características do pesquisador, do ponto de vista dos estudantes em formação psicodramática. 
Assim, tivemos como finalidade última contribuir para o fortalecimento da pesquisa sociodramática, integrando conhecimentos teóricos e a práticos, permeados da reflexão crítica.

\section{METODOLOGIA}

Para alcançar o objetivo proposto, desenvolvemos uma pesquisa-ação com um grupo de estudantes do Curso de Psicodrama - Níveis I e II, durante o Módulo de Metodologia de Pesquisa. O grupo, com sete estudantes presentes, estava interessado em construir um projeto de pesquisa, um dos requisitos para a formação que cursavam; portanto, esse era um assunto de interesse comum. Comuns também eram outros sentimentos manifestados inicialmente: a insegurança como pesquisadores e a necessidade de aprofundar conhecimentos em metodologia sociodramática.

A sessão principal de recolhimento de dados foi desenvolvida através das etapas clássicas do sociodrama. Durante o aquecimento específico foram entregues cartões a cada participante, nos quais deveriam escrever as suas reflexões e afixar em cartazes, cujos títulos já se pretendiam como as categorias prévias de análise: "Competências de um pesquisador"; "Características/valores pessoais do pesquisador"; "Necessidades de transformações no âmbito da pesquisa”; e "Medos, inseguranças e dificuldades que enfrenta um pesquisador".

No final do aquecimento confirmamos que o tema protagônico da sessão sociodramática era o papel do pesquisador e que também já possuíamos os dados prévios a respeito do que é ser um pesquisador sociodramático, do ponto de vista dos próprios estudantes.

$\mathrm{Na}$ dramatização, considerando as orientações de Merengué (2006), que diferencia as dramatizações com fins investigativos, justamente pelo recorte objetivo antecipadamente feito, buscamos validar os dados coletados na etapa anterior a respeito do que é ser pesquisador. Assim, foi feito o convite para os elementos do grupo ocuparem a cadeira colocada no centro do palco com o seguinte título: "O lugar desejado — pesquisador que utiliza o sociodrama como metodologia para pesquisar com espontaneidade, criatividade e liberdade”. Três estudantes revezaram a ocupação da cadeira e o diretor foi questionando, em forma de entrevista, se concordavam com as afirmações afixadas em cada um dos cartazes, se desejavam alterar, acrescentar ou retirar algum item. A plateia também participou sugerindo e questionando. Assim, tivemos os dados validados, refletidos e analisados em conjunto com o grupo. Os dados resultantes nessa fase estavam distribuídos pelos quatro cartazes, que constituíram as categorias de análise.

No compartilhamento foram apresentados os sentimentos sobre a participação na atividade, na sua totalidade positivos. Completando a sessão, no processamento teórico apresentamos e debatemos o sociodrama como metodologia da pesquisa, com as suas principais características, já descritas na introdução deste trabalho.

As etapas de aquecimento específico, dramatização e compartilhamento foram gravadas em áudio e vídeo, com autorização dos participantes, que também assinaram o Termo de Consentimento Livre e Esclarecido.

Durante todas as etapas, o diretor (pesquisador) realizou a observação participante e, durante a dramatização, utilizou a entrevista como técnica dialogal, promovendo a maior participação dos elementos do grupo.

\section{APRESENTAÇÃO E DISCUSSÃO DOS DADOS}

Os dados aqui apresentados podem ser visualizados de dois ângulos, porém integrados:

1. Do ponto de vista da problemática eleita no sociodrama relatado - o pesquisador sociodramático, cujos resultados principais são visualizados através das categorias previamente propostas;

2. Do ponto de vista do sociodrama como metodologia da pesquisa, cuja análise e discussão dos dados vão permeando a apresentação da sessão de sociodrama desenvolvida com os estudantes. 
Inicialmente, verificamos que a temática proposta para o sociodrama era de interesse do grupo, isto é, eles eram os atores em fase de construção e de reconhecimento das suas capacidades enquanto pesquisadores sociopsicodramatistas.

Dentre os vários princípios indicados por Gomes (2015) para a análise qualitativa dos dados, dois marcaram especialmente o início da nossa análise: contextualizar os atores e valorizar relatos validados pelos próprios atores.

A seguir, apresentamos as quatro categorias propostas previamente, acompanhadas de algumas transcrições que foram confirmadas pelo grupo:

1. Competências de um pesquisador: estudo, conhecimento, comunicação.

"Sou estudiosa, gosto de ler, possuo boa comunicação (emissão, recep̧ção e percepção), entendo das ferramentas tecnológicas, sou interessada, determinada, tenho habilidades com tecnologia". Durante a dramatização recebeu o seguinte acréscimo: "Tenho boa desenvoltura na direçãolação".

2. Características/valores pessoais do pesquisador: ética, compreensão empática, respeito, determinação e dedicação. "Sou ética, sou alegre, proponho o novo, julgo menos, estimulo o diferente. Procuro propor de forma livre. Sou compreensiva. Respeito. Empatia”; "Adorar escrever e pesquisar, determinação, comprometimento em desenvolver um bom trabalho".

3. Necessidades de transformações no âmbito da pesquisa: produção, divulgação, espaços de partilha mais flexíveis com espontaneidade.

"Publicar/registrar/relatar encontros vividos, propostas, descobertas, reformulaçöes. Criar hábito de escrever/publicar, compartilhar"; "Contribuir para reflexão sobre a formação de psicodramatistas. Colaborar para termos mais espaços de discussão e construção do método"; "No meio acadêmico-pesquisa: menos rigidez e mais espontaneidade".

4. Medos, inseguranças e dificuldades que enfrenta um pesquisador: não conseguir transmitir o que deseja; críticas externas; bloqueio.

"Crítica por parte de colegas psicodramatistas. Não ter estruturado ou emperrar em algum ponto".

Por meio do sociodrama foi possível justificar as afirmações. Por exemplo, uma estudante justificou porque considerava importante ao pesquisador ter alegria: “...para que as pessoas se manifestem, coloquem as suas ideias verdadeiras, a alegria ajuda. Quando eu participo com a minha alegria, existe um convite para que as pessoas compartilhem as suas ideias".

O sociodrama, como método de ação, possibilitou informações para além das palavras proferidas; os movimentos corporais também manifestaram informações importantes. No processo de análise dos dados, a plateia comunicou livremente se concordava, se desejava acrescentar, subtrair, modificar alguma coisa nas afirmações afixadas.

Também pudemos constatar uma rica troca de informações e, ao mesmo tempo, desejo de abertura: “...eu posso partilhar contigo... a dança ... toda expressão artística ... o olhar da antroposofia ... a pintura... você está estimulando vários lugares, vários sentidos que podem te ajudar enquanto ser pesquisador..."

O debate travado também permitiu reflexão, reconhecimento e respeito pelas diferenças, como por exemplo na manifestação: "É bem particular, eu coloquei essa, porque para mim é importante: psicodrama online."

Várias manifestações de satisfação com a informação produzida merecem destaque: "Tô me sentindo cada vez mais pesquisadora"; "Ai que lindo?"; "Nossa, adorei”; "Somos os apaixonados pelo psicodrama, né?".

Ao compartilharem desejos de transformação, também discordaram e esclareceram termos. Por exemplo, propuseram trocar o termo "psicoterapêutico" por "terapêutico", para ampliar e incluir aqueles que não eram psicólogos. Verifica-se o sociodrama como método que facilita a inclusão e a consideração do outro como sujeito e ator.

Por meio dos diálogos observados, constatou-se que o grupo tinha integrado como objetivo próprio: pesquisar, relatar e divulgar as experiências.

No entanto, desejavam transformar a maneira de se fazer pesquisa: "escreve o que você pensa, o que ficou para você, o que você pensa sobre isso... você aceita poder dialogar com os autores". 
O grupo foi revendo os medos e inseguranças relativos a ser um pesquisador e foram concordando com eles. No entanto, no desenrolar do debate consideraram os medos mais como desafios a serem enfrentados: "Isso não é um risco, é uma realidade... porque estamos pesquisando realidade em movimento... dinâmico... o projeto tem que ser projetado com o andar... essa versatilidade é dada na nossa própria formação no psicodrama". E "Isso vai enriquecendo a nossa prática... isso é muito interessante - a flexibilidade".

Caminhando para a finalização da sessão, foi possível a percepção da evolução do entendimento do sociodrama como metodologia da pesquisa, assim como se identificou o reconhecimento das competências necessárias para o papel de pesquisador e da incorporação dos conceitos e teoria: "Eu consegui me posicionar mais adiante... até agora a gente estava em role playing, agora vem o role creating... criar...”.

Esses resultados vão ao encontro do que nos apresentou Moreno: uma ciência da ação inicia-se com dois verbos — ser e criar - e com três substantivos — atores, espontaneidade e criatividade (Moreno, 2008).

O compartilhamento foi no sentido de estimular o desenvolvimento de trabalhos, reconhecendo a importância do sociodrama para a resolução das próprias questões do grupo, como verificamos nas transcrições a seguir:

"Isso é importante para o meu processo de desenvolvimento... até isso a gente tem que ter autonomia..."; "Me deu empolgação, me deu vontade de tratar de ler, começar escrever, buscar informaçôes para ler... tá vindo numa construção muito legal, tanto dessas aulas, como de outras... as ideias estão clareando"; "Foi muito boa a troca, ajuda muito".

No caso aqui relatado, os membros do grupo ficaram mais encorajados e motivados a desenvolver seu papel de pesquisador sociodramático, o que destaca duas das principais vantagens do método: sua pontencialidade transformadora e o reconhecimento dos participantes como sujeitos dessa transformação. Outras pontecialidades do método (espontaneidade, criatividade, interação grupal, aprendizagem) vão ao encontro dos resultados encontrados numa pesquisa-ação no âmbito da pedagogia psicodramática desenvolvida por Sombrio e Bond (2018).

\section{CONSIDERAÇÕES FINAIS}

O sociodrama como metodologia da ação impulsionou para a ação transformadora. Fortaleceu o grupo e mostrou caminhos, soluções para as questões e conflitos apresentadas pelo próprio grupo. Não menos importante será destacar que permitiu ao grupo o autorreconhecimento das suas competências e valores, como: interesse, dedicação, empatia, ética, competências comunicacionais, dentre outros.

A utilização do sociodrama permitiu coletar os dados, debater e validar com o grupo, numa construção que interessou aos participantes. $\mathrm{O}$ método sociodramático também promoveu conquistas, criações e transformações, culminando com o reconhecimento da motivação e das competências para investigar, o que resultou em uma satisfação manifestamente reconhecida.

"O principal atributo da ciência deve ser sua permanente disposição para se autoestudar e para discordar de si mesma" (Moreno, 2008, p. 81).

\section{CONTRIBUIÇÃO DOS AUTORES}

Conceitualização: Feijó N, Ferracini L; Investigação: Feijó N, Escrita: Feijó N, Ferracini L; Rascunho Original: Feijó N, Ferracini L.

\section{DISPONIBILIDADE DE DADOS DE PESQUISA}

Dados serão enviados mediante solicitação. 


\section{FINANCIAMENTO}

Não se aplica.

\section{AGRADECIMENTO}

Não se aplica.

\section{REFERÊNCIAS}

Brito, V. (2006). Um convite à pesquisa: Epistemologia qualitativa e psicodrama. In A. M. Monteiro, D. Merengué \& V. Brito, Pesquisa qualitativa e psicodrama (pp. 13-56). Ágora.

Figusch, Z. (2010). O modelo contemporâneo de sociodrama brasileiro. In M. M. Marra \& H. J. Fleury (Orgs.), Sociodrama: Um método, diferentes procedimentos (pp. 19-41). Ágora.

Fleury, H.J., \& Marra, M.M. (2010). Tendências atuais no campo das intervenções e da aplicação do sociodrama como método. In M. M. Marra \& H. J. Fleury (Orgs.), Sociodrama: Um método, diferentes procedimentos (pp. 13-18). Ágora.

Gomes, R. (2015). Análise e interpretação de dados de pesquisa qualitativa. In M. C. S. Minayo (Org.), Pesquisa Social: Teoria, método e criatividade (34a ed., pp. 79-108). Vozes.

Iunes, A. L. S., \& Conceição, M. I. G. (2017). Intervenção psicodramática em ato: Ampliando as possibilidades. Revista Brasileira de Psicodrama, 25(2), 19-27. https://doi.org/10.15329/2318-0498.20170018

Merengué, D. (2006). Psicodrama e investigação científica. In A. M. Monteiro, D. Merengué \& V. Brito. Pesquisa qualitativa e psicodrama (pp. 57-87). Ágora.

Moreno, J. L. (2008). Quem sobreviverá. Daimon. Edição do estudante.

Nery, M. P. (2010). Grupos e intervenção em conflitos. Ágora.

Ramos, M. E. C. (2008). O agir interventivo e a pesquisa-ação. In M. M. Marra \& H. J. Fleury (Orgs.), Grupos: Intervenção socioeducativa e métodos sociopsicodramático (pp. 45-55). Ágora.

Rozados, D. S. (2018). Em busca do momento: Por uma teoria da temporalidade a partir da obra de Moreno. Revista Brasileira de Psicodrama, 26(2), 96-107. https://doi.org/10.15329/2318-0498.20180030

Sombrio, C. A., \& Bond, E. O ensino da pedagogia psicodrmática como método para novas aprendizagens. Revista Brasileira de Psicodrama, 26(1), 140-146. https://doi.org/10.15329/23180498.20180007 